\title{
HUBUNGAN MOTIVASI BELAJAR DENGAN HASIL PEMBELAJARAN BAHASA INDONESIA BAGI PENUTUR ASING (BIPA) PADA MAHASISWA SEMESTER 7 PROGRAM STUDI PENDIDIKAN BAHASA DAN SASTRA INDONESIA FKIP UNIVERSITAS MUHAMMADIYAH TANGERANG
}

\author{
Agus Sulaeman ${ }^{1} \&$ Winda Dwihudhana ${ }^{2}$ \\ 1,2 Universitas Muhammadiyah Tangerang \\ Jl. Perintis Kemerdekaan I No.1, Babakan, Kec. Tangerang, Kota Tangerang, Banten \\ Email: sultanwahyu13@gmail.com¹,windhana89@gmail.com²
}

\begin{abstract}
Abstrak
Penelitian ini bertujuan untuk mengetahui hubungan motivasi belajar dengan hasil pembelajaran Bahasa Indonesia Penutur Asing (BIPA) mahasiswa semester 7 Prodi Bahasa dan Sastra Indonesia. Metode penelitian yang digunakan adalah metode kuantitatif dengan desain korelasi. Instrumen penelitian yang digunakan adalah wawancara, observasi, dan kuisioner pernyataan kepada 40 mahasiswa semester 7 pada matakuliah Bahasa Indonesia bagi Penutur Asing. Hal ini dilakukan untuk mengetahui hubungan motivasi belajar terhadap hasil pembelajaran dengan menggunakan uji korelasi, determinasi, dan uji signifikansi. Tujuannya adalah untuk meningkatkan dan mengevaluasi hasil pembelajaran. Berdasarkan hasil analisis perhitungan dengan menggunakan rumus koefisien korelasi pearson diperoleh pengaruh korelasi positif antara motivasi belajar terhadap hasil pembelajaran Bahasa Indonesia, yaitu sebesar $r=0.50$ dengan kategori cukup kuat $(0,40-0,599)$. Dengan demikian, berdasarkan hasil pengujian rumus tersebut, maka $t_{\text {hitung }}>t_{\text {tabel }}$ yaitu $0,62>0,31$, artinya bahwa $\mathrm{H}_{0}$ ditolak dan $\mathrm{H}_{1}$ diterima. Maknanya, motivasi belajar sebagai variabel $\mathrm{X}$ memberi pengaruh yang signifikan terhadap hasil pembelajaran bahasa Indonesia sebagai variabel $\mathrm{Y}$. Maka, materi pembelajaran BIPA tepat untuk dirancang.
\end{abstract}

Kata kunci: Motivasi Belajar, Hasil Pembelajaran, BIPA

\section{The RELATIONSHIP BETWEEN LEARNING MOTIVATION TOWARD LEARNING ACHIEVEMENT Of INDONESIAN LANGUAGE FOR NON NATIVE SPEAKER (BIPA) at $7^{\text {th }}$ SEMESTER STUDENTS IN INDONESIAN LANGUAGE AND LITERATURE EDUCATION STUDY PROGRAM OF FKIP MUHAMMADIYAH TANGERANG UNIVERSITY}

\begin{abstract}
This study aims to determine the relationship between learning motivation towards the learning achievement of Indonesian language for non native speakers (BIPA) at $7^{\text {th }}$ semester students in Indonesian Language and Literature Study Program. The research methods used was quantitative method with correlation design. The instruments of research were interviews, observation and questionnaire respondents' statements to 40 students at $7^{\text {th }}$ semester. This was done in order to find out how the relationship between learning motivation and learning achievement by using correlational, determination and significance test. The purpose was to
\end{abstract}


improve and evaluate the learning achievement. Due to the results of the calculation analysis by using Pearson correlation coefficient formula, there was a positive effect of correlation between learning motivation towards the learning achievement, which was equal of $r=0.50$ that includes a fairly strong category $(0.40-0.599)$. The results of testing the formula of $t$ count is $>t$ table that is $0.62>0.31$, which means that $H_{0}$ was rejected and $H_{1}$ was accepted. It means, the learning motivation as variable $X$ has a significant influence on the learning achievement as variable Y. So, BIPA teaching materials are appropriate to be designed.

Keywords: Learning Motivation, Learning Achievement, BIPA

\section{A. Pendahuluan}

Pendidikan adalah usaha sadar dan terencana untuk mewujudkan suasana belajar dan proses pembelajaran (Ihsan, 2005:1). Proses pembelajaran mempunyai tujuan agar peserta didik secara aktif mengembangkan potensi dirinya kepribadian, kecerdasan, akhlak mulia serta keterampilan yang diperlukan dirinya, masyarakat, bangsa, dan negara. Pendidikan menjadi hal penting dalam kehidupan dalam rangka memajukan kualitas individu. Hal tersebut jelas terlihat dari tujuan utama pendidikan yang berarti menanamkan keyakinan dan memfasilitasi proses belajar siswa. Adapun hasil dari proses belajar siswa adalah perolehan belajar, serta pengetahuan tentang belajar dan bagaimana belajar. Perbaikan proses belajar dan mengajar untuk setiap matakuliah, salah satunya adalah matakuliah pengajaran Bahasa Indonesia bagi Penutur Asing atau yang disingkat dengan istilah BIPA.

Pengajaran BIPA sangat bermanfaat untuk dipelajari oleh mahasiswa agar dapat berkomunikasi secara efektif dan efisien sesuai dengan etika yang berlaku, baik secara lisan maupun tulis, menghargai dan bangga menggunakan bahasa Indonesia sebagai bahasa persatuan dan bahasa negara, memahami bahasa Indonesia dan menggunakannya dengan tepat dan kreatif untuk berbagai tujuan, menggunakan bahasa Indonesia untuk meningkatkan kemampuan intelektual, serta kematangan emosional dan sosial, menikmati dan memanfaatkan karya sastra untuk memperluas wawasan, memperhalus budi pekerti, serta meningkatkan pengetahuan dan kemampuan berbahasa, serta menghargai dan membanggakan sastra Indonesia sebagai khazanah budaya dan intelektual manusia Indonesia. 
Dengan mempelajari BIPA di perguruan tinggi, mahasiswa dapat mengenal dirinya, budayanya dan budaya orang lain, mengemukakan gagasan dan perasaan, berpartisipasi dalam masyarakat yang menggunakan bahasa tersebut dan untuk meningkatkan kemampuan peserta didik untuk berkomunikasi dalam bahasa Indonesia dengan baik dan benar, baik secara lisan maupun tulis, serta menumbuhkan apresiasi terhadap hasil karya kesastraan manusia Indonesia. Walaupun menurut Mutoharoh, dkk. (2018:85) pembelajaran bahasa Indonesia untuk mahasiswa asing pasti tidaklah mudah untuk dipelajari, pasti ada saja kendala dalam mempelajarinya, misalnya dialek yang berbeda, pengucapan yang berbeda, struktur kalimat yang berbeda, dan budaya yang berbeda. Salah satu faktor untuk memahami bahasa Indonesia bagi penutur asing adalah dengan meningkatkan motivasi belajar.

Sementara itu, motivasi dan belajar merupakan dua hal yang saling mempengaruhi. Belajar merupakan tingkah laku secara relatif permanen dan secara potensial terjadi dari hasil praktik atau penguatan yang dilandasi tujuan untuk mencapai tujuan tertentu. Sedangkan motivasi belajar timbul karena faktor intrinsik, yang berupa hasrat dan keinginan berhasil dan dorongan kebutuhan belajar, dan harapan akan cita-cita. Adapun faktor intrinsiknya adalah adanya penghargaan, lingkungan belajar yang kondusif, dan kegiatan belajar yang menarik. Hakikat motivasi belajar adalah dorongan internal dan eksternal pada siswa-siswi yang sedang belajar untuk mengadakan perubahan tingkah laku, pada umumnya dengan beberapa indikator atau unsur yang mendukung. Hal itu mempunyai peranan besar dalam keberhasilan seseorang dalam belajar.

Sardiman (2011:41) mengatakan bahwa motivasi belajar adalah merupakan faktor psikis yang bersifat nonintelektual. Peranannya yang khas adalah penumbuhan dalam gairah pembelajaran. Hasil pembelajaran di kelas akan optimal apabila didukung oleh motivasi belajar yang tepat. Dalam belajar, motivasi memegang peranan penting dan merupakan syarat mutlak dalam belajar. Di sekolah sering sekali terdapat anak yang malas, tidak menyenangkan, suka membolos, dan sebagainya. Itu semua merupakan bentuk dari motivasi belajar yang kurang. 
Dari uraian tersebut tampak bahwa dalam motivasi dibedakan menjadi dua jenis yaitu motivasi instrinsik dan motivasi ekstrinsik. Motivasi instrinsik, menurut Sardiman (2011:65) merupakan motif-motif yang menjadi aktif dan berfungsi tidak perlu dirangsang dari luar karena dalam diri setiap individu sudah ada dorongan untuk melakukan sesuatu. Faktor-faktor yang mempengaruhi motivasi intrinsik: 1) adanya kesadaran anak. Motivasi memang berhubungan dengan kebutuhan seseorang yang memunculkan kesadaran untuk melakukan aktivitas belajar. 2) Ketekunan belajar, seorang anak yang termotivasi untuk belajar sesuatu, akan berusaha mempelajarinya dengan baik dan tekun, dengan harapan memperoleh hasil yang baik. Berarti motivasi sangat berpengaruh terhadap ketahanan dan ketekunan dalam belajar (Uno, 2006: 28). 3) Konsentrasi belajar, yaitu memusatkan segenap kekuatan perhatian pada situasi belajar. Di dalam konsentrasi ini diperlukan keterlibatan mental secara detail, sehingga tidak perhatian sekedarnya (Sardirman 2011:40).

Kemudian, motivasi ekstrinsik menurut Dimyanti (2006:22), merupakan motivasi yang dapat berubah menjadi motivasi instrinsik jika siswa menyadari pentingnya belajar. Motivasi ekstrinsik juga sangat diperlukan oleh siswa dalam pembelajaran karena adanya kemungkinan perubahan keadaan siswa dan juga faktor lain seperti kurang menariknya proses belajar mengajar bagi siswa. Faktorfaktor yang mempengaruhi motivasi ekstrinsik: 1) iklim belajar yang kondusif. Iklim belajar yang kondusif merupakan tulang punggung dan faktor pendorong yang dapat memberikan daya tarik tersendiri bagi proses pembelajaran. Sebaliknya, iklim belajar yang kurang menyenangkan akan menimbulkan kejenuhan dan rasa bosan. 2) Strategi pembelajaran, dalam dunia pendidikan, strategi pembelajaran dapat diartikan sebagai perencanaan yang berisi tentang rangkaian kegiatan yang didesain untuk mencapai tujuan pembelajaran tertentu. Untuk mengimplementasikan rencana yang sudah disusun tersebut diperlukan upaya atau cara yang digunakan untuk melaksanakan strategi ini yang dinamakan metode (Sanjaya, 2009:124). 3) Guru merupakan unsur manusiawi dalam pendidikan. Kehadiran guru mutlak diperlukan di dalamnya. Jika hanya ada anak didik, tetapi guru tidak ada, maka tidak akan terjadi kegiatan belajar mengajar di sekolah. Jangankan ketiadaan guru, kekurangan guru saja sudah menjadi 
masalah (Djamarah, 2008:151). Selain itu, motivasi ektrinsik ini dapat muncul bila guru memberikan model pembelajaran yang tepat dan menyenangkan karena sesungguhnya guru dalam kegiatan pembelajaran dituntut untuk memilih model pembelajaran yang tepat, efektif, dan inovatif sehingga tujuan dari kegiatan pembelajaran yang diharapkan siswa mengalami pengalaman belajar yang mampu mengubah perilakunya sesuai tuntutan dalam kompetensi dasar (Noermanzah, 2018:172).

Berdasarkan penjabaran tersebut, maka motivasi belajar dapat diartikan sebagai adanya kesadaran, ketekunan dan kosentrasi siswa dalam melaksanakan belajar. Selain itu, iklim juga sangat berpengaruh sebagai daya tarik untuk menciptakan suasana dalam proses pembelajaran yang sangat menyenangkan. Motivasi belajar dianggap penting di dalam proses belajar dan pembelajaran dilihat dari segi fungsi dan nilainya atau manfaatnya. Hal ini menunjukkan bahwa motivasi belajar mendorong timbulnya tingkah laku dan mempengaruhi serta mengubah tingkah laku siswa.

Mc. Donald, (dalam Hamalik, 2003:158) menjelaskan motivasi sebagai perubahan energi dalam pribadi seseorang yang ditandai dengan timbulnya perasaan, tindakan, dan reaksi dalam mencapai tujuan. Siswa yang memiliki motivasi kuat akan mempunyai banyak energi untuk melakukan kegiatan belajar. Seorang siswa yang mempunyai intelegensi cukup tinggi boleh jadi menggalami kegagalan karena kurangnya motivasi. Kemudian, menurut Sardiman (2011: 85) ada tiga fungsi motivasi yaitu: (1) mendorong manusia untuk berbuat, jadi sebagai penggerak atau motor yang melepaskan energi; (2) menentukan arah perbuatan, yakni ke arah tujuan yang hendak dicapai; dan (3) menyeleksi perbuatan, yakni menentukan perbuatan mana yang harus dikerjakan yang serasi guna mencapai tujuan dengan menyisihkan perbuatan-perbuatan yang tidak bermanfaat bagi tujuan tersebut.

Selain itu, indikator motivasi mempunyai peranan yang sangat penting dalam rancangan persiapan pembelajaran, karena proses belajar mengajar yang baik harus direncanakan dengan baik pula. Pengembangan indikator yang baik akan mengukur kompetensi dasar dan standar kompetensi yang dikehendaki oleh kurikulum di sekolah maupun perguruan tinggi. Indikator merupakan penanda 
pencapaian kompetensi dasar yang ditandai oleh perilaku siswa yang terukur mencakup sikap, pengetahuan, dan keterampilan. Indikator dikembangkan sesuai dengan karakter peserta didik, mata pelajaran, satuan pendidikan, potensi daerah dan dirumuskan dalam kata kerja operasional yang terukur dan atau dapat diobservasi.

Indikator yang dikembangkan dengan benar dapat membantu memandu pemilihan bahan ajar, metode pembelajaran, dan alur pelaksanaan pembelajaran. Apabila keselarasan antara bahan ajar, metode, dan alur pembelajaran dirancang dengan baik melalui penetapan indikatornya, maka niscaya ketercapaian kompetensi yang ditargetkan dapat tercapai dengan baik.

Selain itu, Menurut Keke (2008:11) motivasi belajar siswa meliputi beberapa dimensi yang dapat dijadikan indikator, yaitu sebagai berikut: ketekunan dalam belajar, ulet dalam menghadapi kesulitan, minat dan ketajaman perhatian dalam belajar, berprestasi dalam belajar, dan mandiri dalam belajar.

Hasil penelitian relevan pernal dilakukan oleh Yanto \& Ruhenda (2015) tentang Hubungan antara Kecerdasan Linguistik dan Motivasi Belajar dengan Hasil Belajar Bahasa Indonesia Siswa Kelas VI di SDN Cihideung Ilir 04 Kecamatan Ciampea. Hasil penelitian ini menunjukkan bahwa terdapat hubungan yang signifikan Hubungan antara Kecerdasan Linguistik dan Motivasi Belajar dengan Hasil Belajar Bahasa Indonesia Siswa Kelas VI di SDN Cihideung Ilir 04 Kecamatan Ciampea. Penelitian ini berbeda karena variabel y-nya lebih kepada hasil belajar bahasa Indonesia secara umum sedangkan dalam penelitian ini lebih kepada hasil belajar bahasa Indonesia bagi penutur asing. Oleh karena itu, penting dikaji permasalahan motivasi yang dimiliki oleh mahasiswa di dalam proses pembelajaran BIPA, terutama sejauh mana dan seperti apa hubungan motivasi belajar dengan hasil belajar BIPA pada mahasiswa semester 7 Program Studi Pendidikan Bahasa dan Sastra Indonesia FKIP, Universitas Muhammadiyah Tangerang. 


\section{B. Metode Penelitian}

Metode penelitian yang digunakan adalah metode penelitian kuantitatif dengan desain korelasi untuk melihat hubungan antara motivasi belajar mahasiswa terhadap hasil belajar BIPA. Populasi pada penelitian ini adalah seluruh mahasiswa semester 7 Kelas Al dan A2 Program Studi Pendidikan Bahasa dan Sastra Indonesia FKIP Universitas Muhammadiyah Tangerang Kota Tangerang yang berjumlah 40 orang. Sampel yang diambil sebagai responden yaitu para mahasiswa dengan teknik probability sampling yaitu teknik sampling yang memberikan peluang sama bagi setiap anggota populasi untuk dipilih menjadi anggota sampel. Pengambilan sampel dilakukan secara acak dengan memperhatikan status yang ada dalam populasi tersebut. Menurut Arikunto (2006:73) apabila subjeknya kurang dari 100 orang lebih baik diambil semua sehingga penelitiannya merupakan penelitian populasi. Maka, sampel dalam penelitian ini berjumlah 40 responden.

Data yang diperoleh dalam penelitian ini dikumpulkan dengan menggunakan metode kuesioner dan tes. Dalam penelitian ini kuesioner digunakan untuk mengumpulkan data dari para responden yang telah ditentukan. Kuesioner berisi pernyataan tentang tanggapan pemustaka terhadap penerapan sanksi admistratif pengembalian bahan pustaka. Pernyataan disusun dengan memperhatikan prinsip-prinsip penulisan kuesioner seperti isi dan tujuan pertanyaan, bahasa yang digunakan, tipe dan bentuk pertanyaan, panjang pertanyaan, urutan pertanyaan, dan penampilan fisik kuesioner. Untuk tes menggunakan tes esai untuk melihat kemampuan bahasa Indonesia bagi penutur asing. Kemudian, teknik analisis data menggunakan uji korelasi produk moment untuk melihat tingkat hubungan motivasi belajar dengan hasil belajar BIPA pada mahasiswa semester 7 Program Studi Pendidikan Bahasa dan Sastra Indonesia FKIP, Universitas Muhammadiyah Tangerang.

\section{Hasil Penelitian dan Pembahasan}

\section{Hasil Penelitian}

Hasil uji coba instrumen kuesioner berupa hasil uji reliabilitas (kehandalan) terhadap pernyataan yang merupakan indikator dari kedua variabel. Butir 
kuesioner dikatakan reliable (handal) bila memiliki koefisien kehandalan atau alpha $(\sqrt{ })$ sebesar $\geq 0,05(5 \%)$. Setiap variabel diterjemahkan kedalam 10 butir pernyataan. Uji realibilitas variable $X$ (motivasi belajar) menggunakan metode Alpha Cronbach dengan hasil 0,36 . Disimpulkan bahwa $r_{\mathrm{ca}}($ Variabel $X)=0.36$ (reliabel karena nilai $r_{\text {hitung }}$ lebih besar dari pada nilai $r_{\text {tabel }}$ product moment yaitu $0.36>0.31$ ). Sementara itu, reliabilitas variabel hasil pembelajaran ( $Y$ ) diperoleh nilai sebesar 6,2. Disimpulkan bahwa $r_{c a}($ Variabel $Y)=0.48$ (reliabel karena nilai $r_{\text {hitung }}$ lebih besar dari pada nilai $r_{\text {tabel }}$ product moment yaitu $0.48>0.31$ ). Berikut ditunjukkan hasil coba reliabilitas kuesioner motivasi belajar dan tes hasil pembelajaran.

\section{Tabel 1. Hasil Uji Reliabilitas Kuesioner dan Tes Hasil Pembelajaran}

Bahasa Indonesia bagi Penutur Asing

\begin{tabular}{cccl}
\hline Variabel & $\mathbf{r}_{\text {hitung }}$ & $\mathbf{r}_{\text {tabel }}$ & Status \\
\hline Motivasi Belajar & 0.36 & 0,31 & Reliable \\
\hline Hasil Pembelajaran & 0.48 & 0,31 & Reliable \\
\hline
\end{tabular}

Berdasarkan data dari hasil uji reliabilitas terhadap indikator kedua variabel tersebut, maka dapat disimpulkan bahwa setiap butir kuesioner dan tes dapat dijadikan sebagai alat ukur guna mengungkapkan motivasi belajar dan hasil pengajaran bahasa Indonesia bagi penutur asing mahasiswa semester 7 Program Studi Pendidikan Bahasa dan Sastra Indonesia FKIP Universitas Muhammadiyah Tangerang.

Selanjutnya, hubungan motivasi belajar terhadap terhadap hasil pengajaran bahasa Indonesia bagi penutur asing mahasiswa semester 7 Program Studi Pendidikan Bahasa dan Sastra Indonesia FKIP Universitas Muhammadiyah Tangerang dianalisis menggunakan korelasi sederhana dengan menggunakan rumus product moment. Dari hasil analisis perhitungan menggunakan rumus koefisien korelasi pearson ada pengaruh korelasi positif antara motivasi belajar dengan hasil pembelajaran, yaitu sebesar $r=0.50$ yang termasuk kategori cukup kuat $(0,40-0,599)$, maka untuk mengetahui seberapa besar hubungan motivasi belajar dengan hasil pembelajaran adalah dengan menggunakan koefisien determinasi. 
Tabel 2. Pedoman untuk memberikan interpretasi Koefisien Korelasi

\begin{tabular}{cc}
\hline Interval Koefisien & Tingkat Hubungan \\
\hline $0,00-0,199$ & Sangat Lemah \\
$0,20-0,399$ & Lemah \\
$\mathbf{0 , 4 0}-\mathbf{0 , 5 9 9}$ & Cukup Kuat \\
$0,60-0,799$ & Kuat \\
$0,80-1,000$ & Sangat Kuat
\end{tabular}

(Sumber: Sugiyono, 2010:216)

Selanjutnya, untuk mengetahui seberapa besar hubungan motivasi belajar dengan pengajaran bahasa Indonesia bagi penutur asing mahasiswa semester 7 Program Studi Pendidikan Bahasa dan Sastra Indonesia FKIP Universitas Muhammadiyah Tangerang digunakan rumus koefisien penentu atau koefisien Determinasi sebagai berikut :

$$
\begin{aligned}
R & =r^{2} \times 100 \% \\
& =(0,50)^{2} \times 100 \% \\
& =25 \%
\end{aligned}
$$

Hal ini membuktikan bahwa besarnya hubungan motivasi belajar terhadap pengajaran bahasa Indonesia bagi penutur asing mahasiswa semester 7 Program Studi Pendidikan Bahasa dan Sastra Indonesia FKIP Universitas Muhammadiyah Tangerang sebesar $25 \%$ dan sisanya sebesar $75 \%$ dipengaruhi beberapa faktor lainnya.

Dari hasil analisis perhitungan menggunakan rumus koefisien korelasi pearson ada pengaruh korelasi positif antara motivasi belajar terhadap hasil pembelajaran bahasa Indonesia, yaitu sebesar $r=0.50$ yang termasuk kategori cukup kuat (0,40-0,599. Maka, berdasarkan hasil pengujian rumus di atas maka $t_{\text {hitung }}>t_{\text {tabel }}$ yaitu 0,62>0,31 yang artinya bahwa $\mathrm{H}_{0}$ ditolak dan $\mathrm{H}_{1}$ diterima, artinya motivasi belajar $(X)$ mempunyai pengaruh yang signifikan terhadap hasil pengajaran bahasa Indonesia bagi penutur asing $(Y)$.

\section{Pembahasan}

Bahasa Indonesia bagi Penutur Asing atau yang lebih dikenal dengan singkatan BIPA merupakan sebuah pembelajaran yang sedang populer dikembangkan di Indonesia. Sesuai dengan visi dan misi yang di berikan oleh Badan Pengembangan Bahasa dan Perbukuan pembelajaran BIPA diharapkan 
dapat memperkenalkan budaya Indonesia di kancah Internasional (Adryansyah, 2012). Oleh karena itu, diharapkan mahasiswa dapat termotivasi dengan baik untuk menguasai BIPA, sehingga tujuan dari pembelajaran BIPA dapat tercapai dengan baik.

Hasil korelasi antara motivasi mahasiswa terhadap hasil belajar BIPA di dalam penelitian ini menunjukkan bahwa BIPA menjadi satu mata kuliah yang menarik untuk dipelajari. Sebagaimana Megawati (2014:62) mengembangkan media pembelajaran BIPA agar pembelajaran BIPA menjadi lebih menarik dan lebih banyak diminati oleh peserta didik dari berbagai level. Namun, tingkat perbedaan pemahaman yang dimiliki oleh setiap individu, membuat pembelajaran BIPA menjadi sebuah tantangan di dalam pelaksanaan pembelajaran itu sendiri.

Hal ini sejalan dengan penelitian yang dilakukan oleh Suyitno (2007:62) bahwa tingkat pemahaman dan latar belakang budaya yang berbeda akan memberikan perbedaan terhadap hasil penguasaan materi BIPA itu sendiri. Senada dengan hasil penelitian ini bahwa mahasiswa yang memiliki tingkat motivasi yang tinggi, akan dengan mudah menguasai materi pembelajaran BIPA selama proses pembelajaran berlangsung. Begitu juga sebaliknya, mahasiswa yang memiliki motivasi rendah, maka akan mengalami kesulitan untuk menguasai materi pembelajaran BIPA yang diberikan oleh dosen pengampu mata kuliah selama proses pembelajaran berlangsung.

Dengan demikian, dapat dikatakan bahwa motivasi memiliki peran yang strategis di dalam pelaksanaan pembelajaran BIPA. Motivasi dapat menentukan kesuksesan atau keberhasilan dalam penguasaan BIPA. Motivasi dapat menjadi landasan di dalam mengarahkan mahasiswa agar menguasai materi dengan baik dan benar.

\section{Simpulan}

Dari hasil penelitian dan pembahasan dapat disimpulkan bahwa ada hubungan yang kuat dan positif antara motivasi belajar dengan hasil pengajaran bahasa Indonesia bagi penutur asing mahasiswa semester 7 Program Studi Pendidikan Bahasa dan Sastra Indonesia FKIP Universitas Muhammadiyah Tangerang yang ditunjukkan dengan koefisien korelasi sebesar 0,50 (dengan 
koefisien determinasi sebesar $25 \%$ dan sisanya $75 \%$ dipengaruhi oleh beberapa faktor lainnya). Selanjutnya, dari uji signifikasi t hitung didapatkan hasil sebesar 0.62, dimana hasil ini masih lebih besar dari $t_{\text {tabel }}$ sebesar 0,31 yang artinya terdapat hubungan yang signifikan antara motivasi belajar (variabel $X$ ) dengan pengajaran bahasa Indonesia bagi penutur asing (variabel Y).

\section{Daftar Pustaka}

Adryansyah. (2012). Profil BIPA Badan Pengembangan dan Pembinaan Bahasa. Jakarta: Badan Pengembangan Bahasa dan Perbukuan, Kementerian Pendidikan dan Kebudayaan.

Arikunto. S. (2006). Prosedur Penelitian Suatu Pendekatan Praktik. Jakarta: Rineka Cipta.

Aritonang, K. T. (2008). Minat dan Motivasi dalam Meningkatkan Hasil Belajar Siswa. Jurnal Pendidikan Penabur - No.10/Tahun ke-7. http://bpkpenabur.or.id/wp-content/uploads/2015/10/jurnal-No10-Thn7Juni2008.pdf

Dimyanti. (2006). Belajar dan Pembelajaran. Jakarta: PT Rineka Cipta.

Djamarah, S. B. (2008). Psikologi Belajar. Jakarta: Rineka Cipta.

Hamalik, O. (2003). Proses Belajar Mengajar. Jakarta: PT Bumi Aksara.

Ihsan, F. H. (2005). Dasar-Dasar Kependidikan. Jakarta: PT Rineka Cipta.

Megawati, C. (2014). Pengembangan Media Pembelajaran BIPA Tingkat Menengah melalui E-Book Interaktif di Program Incountry Universitas Negeri Malang Tahun 2014. NOSI, 2(1), Februari 2014. Hal 62-70. http://www. pbindoppsunisma.com/wp-content/uploads/2014/04/6. -CitraMegawati-62-70.pdf

Mutoharoh, M., Sulaeman, A., \& Goziyah, G. (2018). Interferensi Morfologi dalam Karangan Narasi Mahasiswa Thailand Semester IV Pendidikan Bahasa dan Sastra Indonesia FKIP Universitas Muhammadiyah Tangerang. Silampari Bisa: Jurnal Penelitian Pendidikan Bahasa Indonesia, Daerah, dan Asing, 1(1), 85. doi:10.31540/silamparibisa.v1i1.10

Noermanzah, N., Abid, S., \& Aprika, E. (2018). Pengaruh Teknik Send a Problem terhadap Kemampuan Menulis Daftar Pustaka Siswa Kelas XI SMA Negeri 4 Lubuklinggau. Jurnal Kajian Bahasa, Sastra dan Pengajaran (KIBASP), 1(2), 172. doi:10.31539/kibasp.v1i2.273 
Agus Sulaeman ${ }^{1} \&$ Winda Dwihudhana ${ }^{2} \quad$ Hubungan Motivasi Belajar dengan Hasil Pembelajaran

Sanjaya, W. (2009). Strategi Pembelajaran Berorientasi Standar Proses Pendidikan. Jakarta: Kencana Prenada Media Group.

Sardiman. (2011). Interaksi dan Motivasi Belajar Mengajar. Jakarta: Rajawali.

Sugiyono. (2010). Metode Penelitian Pendidikan Pendekatan Kuantitatif, Kualitatif, dan $R \& D$. Bandung: Alfabeta.

Suyitno, I. (2007). Pengembangan Bahan Ajar Bahasa Indonesia untuk Penutur Asing (BIPA) berdasarkan Hasil Analisis Kebutuhan Belajar. Wacana, 9 (1), 62-78, http://journal.ui.ac.id/index. php/wacana/article/view/3677

Uno, H. B. (2006). Teori Motivasi \& Pengukurannya: Analisis di Bidang Pendidikan. Jakarta: Bumi Aksara.

Yanto \& Ruhenda. (2015). Hubungan antara Kecerdasan Linguistik dan Motivasi Belajar dengan Hasil Belajar Bahasa Indonesia Siswa Kelas VI di SDN Cihideung llir 04 Kecamatan Ciampea. Jurnal Teknologi Pendidikan, 4(2). doi:10.32832/tek.pend.v4i2.482 